\title{
UCRL-PROC-207902
}

\section{Design of an Illumination Technique to Improve the Identification of Surface Flaws on Optics}

R. R. Prasad, M. Bernacil, J. Halpin, J. Peterson, S. Mills, R. P. Hackel

November 11, 2004

Boulder Damage Symposium XXXVI, Annual Symposium on Optical Materials for High Power Lasers, 2004 Boulder, CO, United States September 20, 2004 through September 22, 2004 
This document was prepared as an account of work sponsored by an agency of the United States Government. Neither the United States Government nor the University of California nor any of their employees, makes any warranty, express or implied, or assumes any legal liability or responsibility for the accuracy, completeness, or usefulness of any information, apparatus, product, or process disclosed, or represents that its use would not infringe privately owned rights. Reference herein to any specific commercial product, process, or service by trade name, trademark, manufacturer, or otherwise, does not necessarily constitute or imply its endorsement, recommendation, or favoring by the United States Government or the University of California. The views and opinions of authors expressed herein do not necessarily state or reflect those of the United States Government or the University of California, and shall not be used for advertising or product endorsement purposes. 


\title{
Design of an illumination technique to improve the identification of surface flaws on optics
}

\author{
Rahul R. Prasad*, Michael Bernacil, John Halpin, John Peterson, Steve Mills and Richard P. Hackel \\ Lawrence Livermore National Laboratory \\ 7000 East Avenue, L-592 \\ Livermore, CA 94550
}

\begin{abstract}
An edge illumination technique has been designed using a monochromatic light source that improves the identification of surface flaws on optics. The system uses a high-resolution CCD camera to capture images of the optics. Conventional edge illumination methods using white light sources have been plagued by light leaking around the optics causing high background levels. The background combined with lower resolution cameras has made it difficult to determine size and intensity characteristics of the flaws. Thus photographs taken of the optics are difficult to analyze quantitatively and do not allow for the detection of small, faintly illuminated sites.

Infrared diodes have been utilized to illuminate large-scale $(43 \mathrm{~cm} \mathrm{x} 43 \mathrm{~cm})$ fused silica optics, and a two-dimensional array CCD camera has been used to collect the image data. Flaw sizes as small as $\sim 10 \mu \mathrm{m}$ have been detected. A set of frames has been built to support the infrared sources where one diode array per side is magnetically attached to the frame. The diodes inject light into the optic causing the sites to illuminate, which can be detected by the camera. A customized mounting design has been implemented to secure the frames to the stage, or base, for image acquisition. The design uses a dual bracket assembly to support the frames. With this design for optical illumination, quantitative data has been obtained of the surface flaws.
\end{abstract}

A comparison of the peak intensity, total integrated intensity and size of the flaws measured in these images and the size of the flaws as measured using a microscope will be presented.

\section{INTRODUCTION}

Over the past few years edge illumination techniques for large-scale fused silica optics have used fiber optic "light bars" using halogen light sources for the identification of surface flaws. This technique has the disadvantage that background scattering of white light causes a low signal-to-noise ratio in the resultant images, causing defects of small size to be masked. An illumination technique that couples light into an optic efficiently and effectively, but has low background scatter would be highly desirable to reduce the size of the "detectable" flaws. We have developed such a technique. In addition, the optics, which are highly valuable, need to be held in a manner that does not cause damage during inspection.

\section{OPTIC MOUNTING}

Custom frames have been designed to safely hold the optics during inspection. The outside of the frame is made of anodized aluminum to provide structural rigidity. The inside of the frame is composed of a delrin housing that uses Teflon coated viton O-rings to hold the optic in a stress-free manner. Acrylic mirrors are used to reflect the light back into the optic and thus reduce background light due to leakage. Figure 1 shows a diagram of the frame and the details of the mirror and O-ring design. In addition the two halves of the frame are secured to one another by means of two latches as shown in Figure 1. This latched arrangement removes the requirement of any screws or tools to be used in the presence of the optic, thus making it more difficult for the optic to be damaged in handling.

\footnotetext{
*Correspondence: (925) 423-0690,prasad4@1lnl.gov
} 


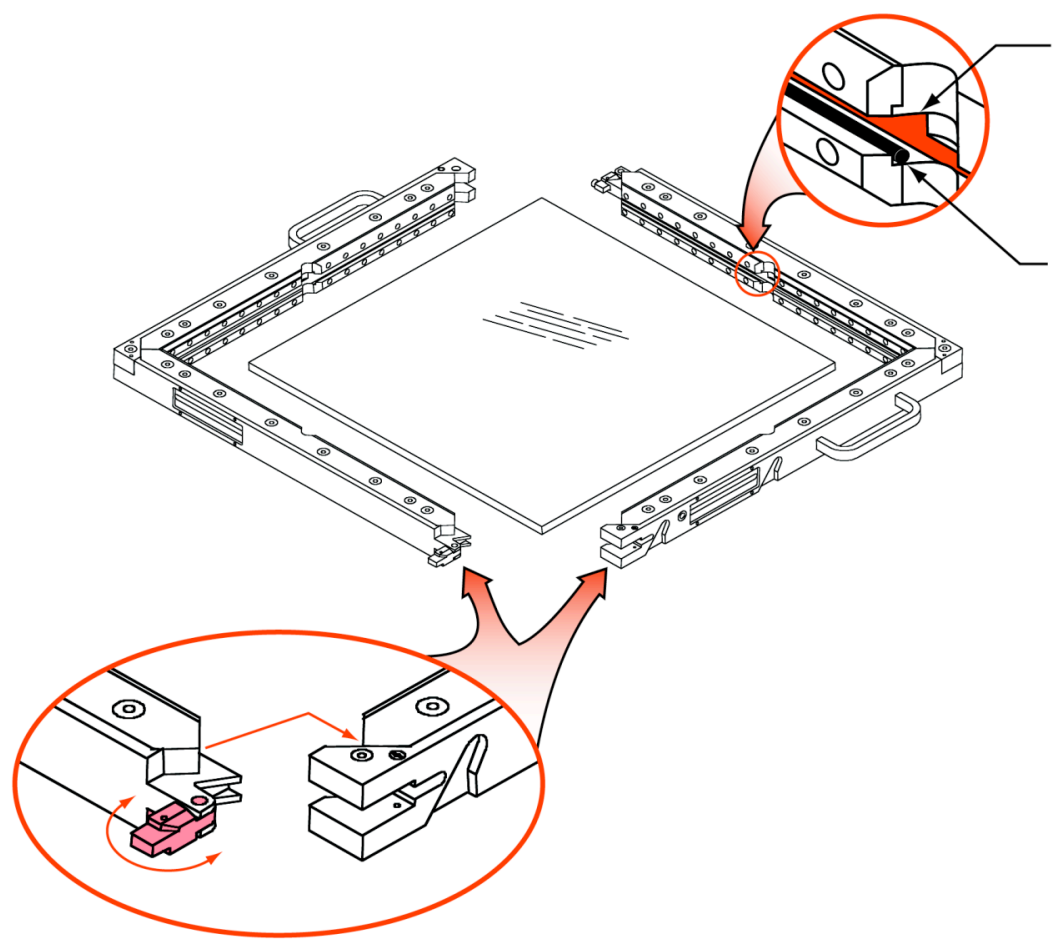

Figure 1: Frame for a $43 \mathrm{~cm} \mathrm{x} 43 \mathrm{~cm}$ optic. The upper right close up shows the acrylic mirrors and O-ring tubing and the lower right close-up shows the latch used to secure the frame.

Custom stage supports have been built to secure the frame to the optical stage during image acquisition. Figure 2 shows the frame held on the stage supports. The frame is held using a set of cams that are located in the supports and a set of cam followers that is located at the sides of the frame. This technique again allows the mounting of the optic on the frame without the use of tools of screwing any retaining bolts that might cause particulates near the surface of the optics.

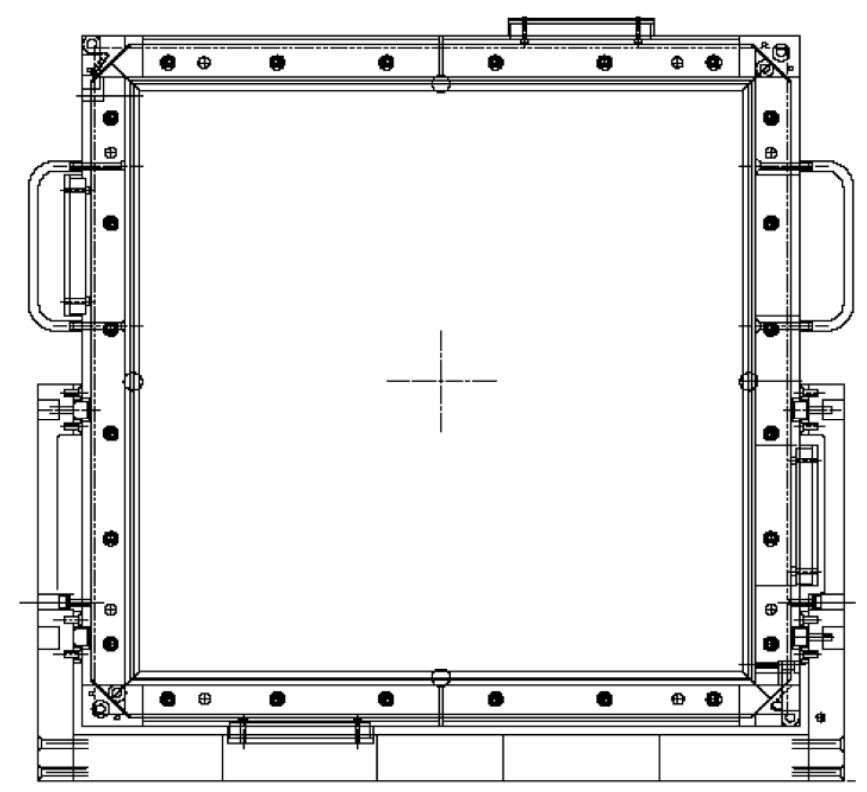

Figure 2: Frame secured to stage supports during imaging. The frame holding the optic is located on the support using a set of cams on the support that ride on cam followers within the frame. 


\section{OPTIC IMAGING}

Figure 3 shows an artist's rendition of an optic being held within the frame and being photographed by the camera shown on the right. The diode arrays plug into the slots, an example of which is shown in the left side of the mounting frame. Infrared diodes have been selected to illuminate the optics when capturing images. If a flaw, or site, is present on the surface of the optic, or is present in the bulk, total internal reflection ends where the site is present and the flaw scatters light out toward the observer. The camera can then detect this illumination scattering effect. A $4000 \times 4000$ pixel array commercial color CCD camera is used to capture the images. This camera uses three filters to generate RGB color response. The transmission of the three filters is shown in Figure 4. It is clear that the three filters transmit almost an equal amount of light at around $810-850 \mathrm{~nm}$. Thus $810 \mathrm{~nm}$ diodes were selected as the illumination source [1].
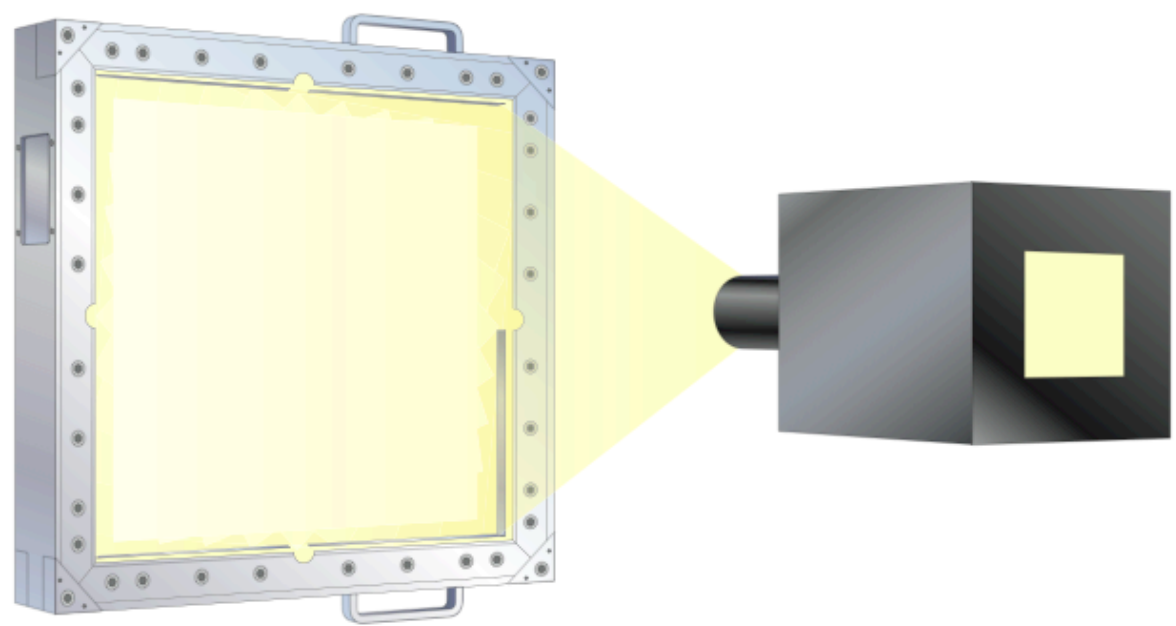

Figure 3: Artist's rendition of the camera and the optic held within the frame during image capture.

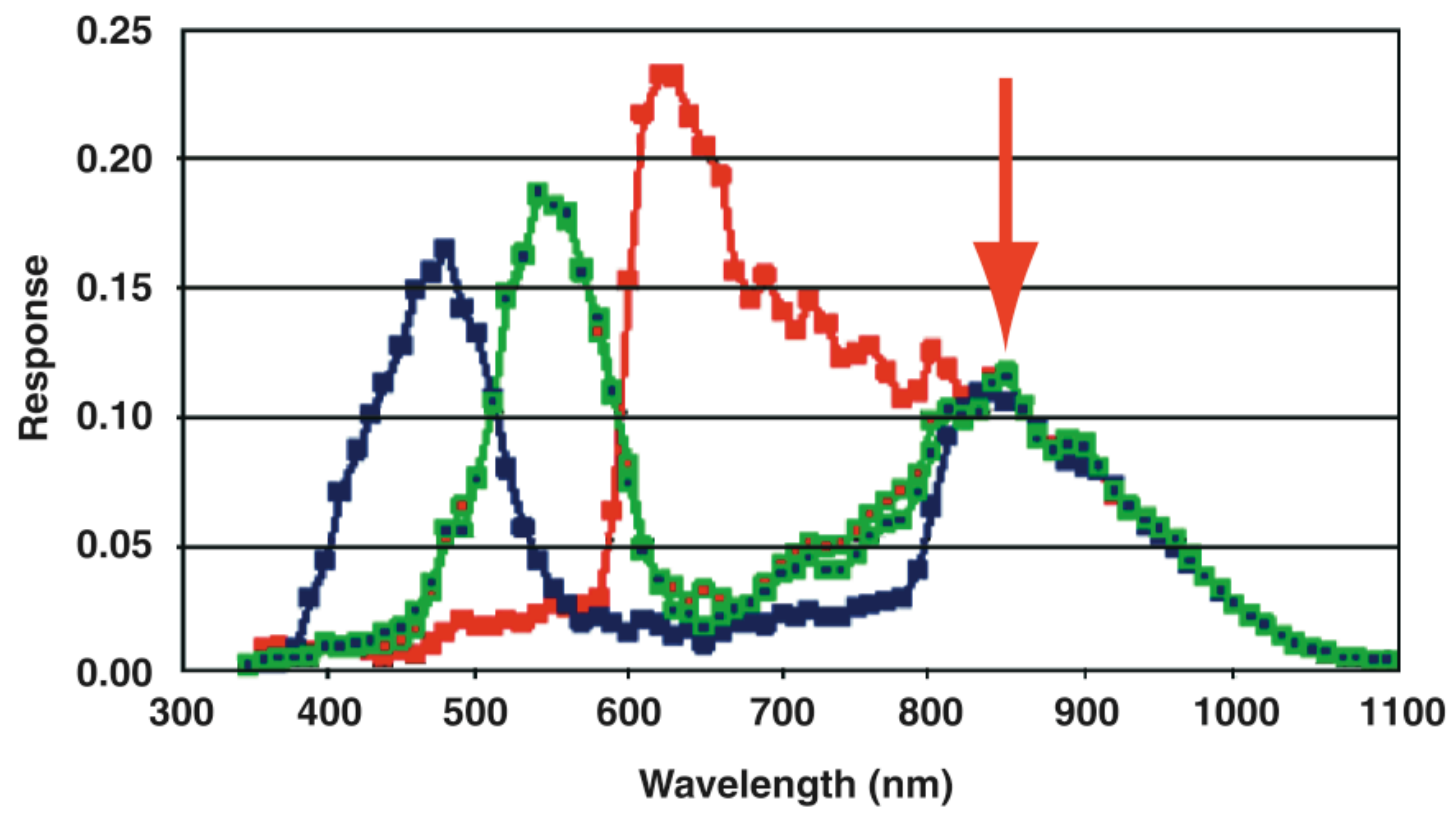

Figure 4: Spectral response of the RGB filters used in the color CCD camera. Note that the response is almost identical in the $810-850 \mathrm{~nm}$ range. 
This imaging system acquires an image of the $43 \mathrm{~cm}$ x $43 \mathrm{~cm}$ optic and stores it as a 16-bit TIFF image in less than 1 minute. Defects that are captured as a bright spot on a dark background can be identified using computer programs that have been developed at the Lawrence Livermore National Laboratory [2].

\section{IMAGE ANALYSIS}

Figure 5 shows a typical image acquired by the illumination technique described above. Flaws identified in this image were then electronically magnified as shown in the inserts. The images shown below the inserts were captured by a microscope in order to more accurately determine the size of the flaws.

\section{Image of full-size optic}

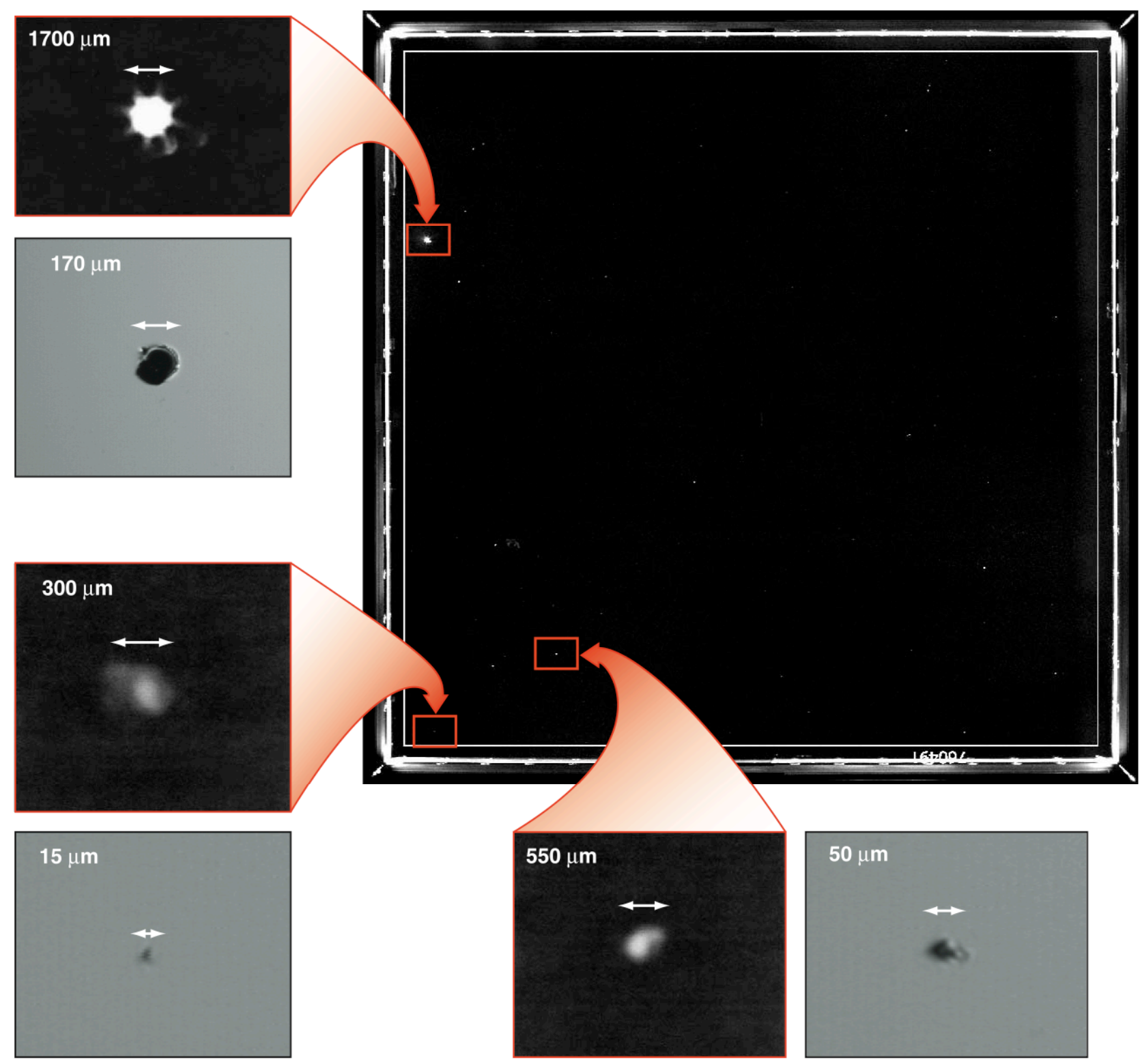

Figure 5: Image of a $43 \mathrm{~cm} \mathrm{x} 43 \mathrm{~cm}$ optic. The inserts show the flaws magnified and imaged using a microscope. 
The sizes of the flaws as measured using the microscope images were compared to parameters measured in the full size images. The size of the flaws in the full size image, the peak intensity of the flaw in the full size image and the integrated intensity over the entire defect in the full size image were compared to the real flaw size as measured in microscope images as displayed in Figure 6. The initial data reveal that although this technique can be utilized to identify small flaws in the optical surface, it is not yet an accurate technique for measuring flaw size.

\section{CONCLUSIONS}

An edge illumination technique has been designed using a monochromatic light source that improves the identification of surface flaws on optics. Due to the high cost per optic , the design emphasized holding the optic safely. Using a high resolution CCD camera, surface features as small as $15 \mu \mathrm{m}$ are identified. Comparison of features identified using this imaging technique and a microscope confirm the ability of this technique to identify the flaw locations in the full-size images. An initial analysis of the image sizes viewed using infrared LED arrays shows that the peak intensity, and the total (integrated) intensity of the sites do not provide a strong correlation with the actual image size viewed with a microscope. More work is being done to get a better quantitative correlation between image parameters and feature size.
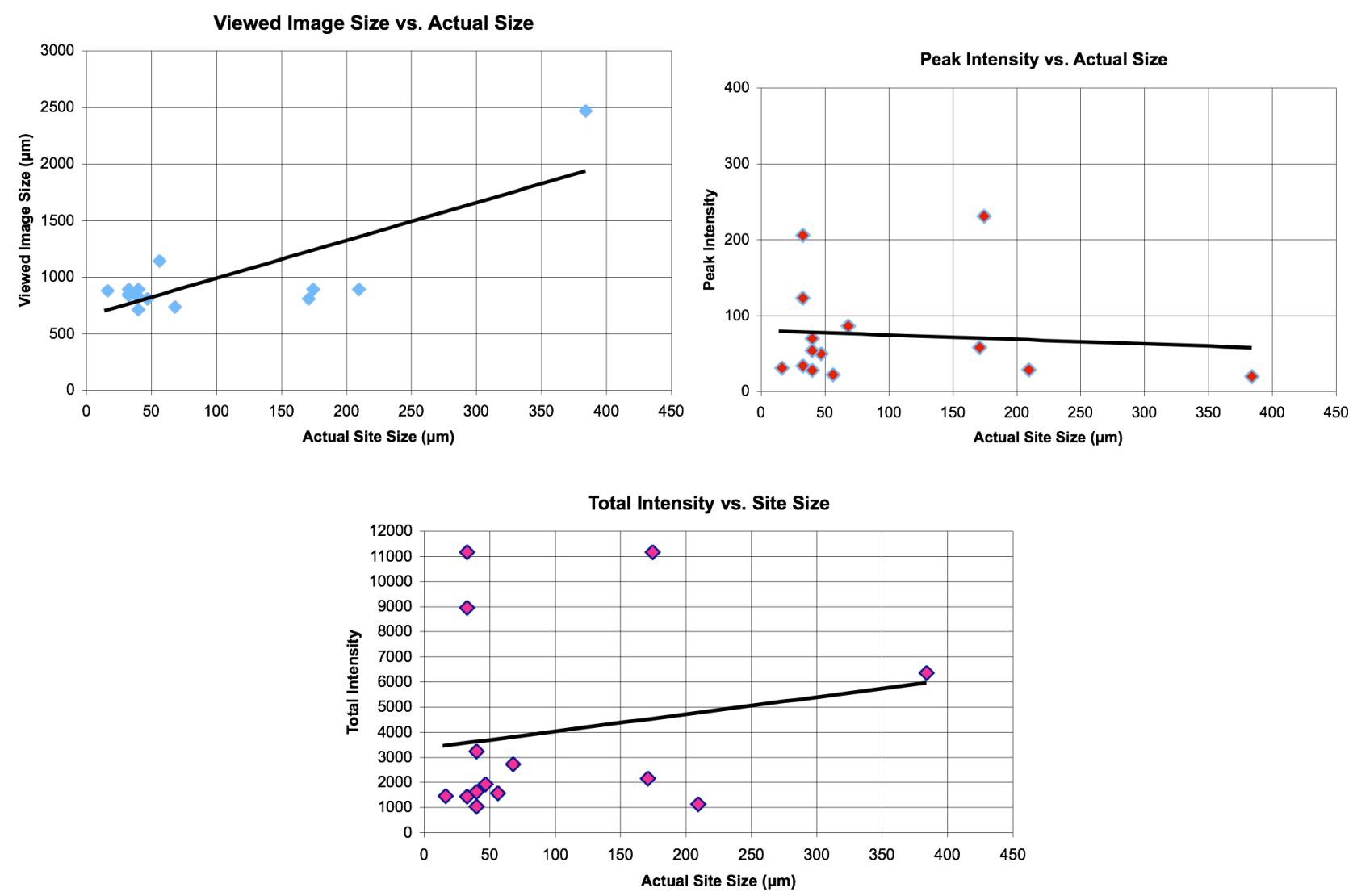

Figure 6: Actual flaw size measured in microscope images compared to the flaw size, peak intensity and total integrated intensity measured in the full size images.

\section{REFERENCES}

1. R. R. Prasad, J. R. Bruere, J. M. Halpin, P. Lucero, S. Mills, M. Bernacil, R. P. Hackel, "Design of a production process to enhance optical performance of $3 \omega$ optics," Proc. SPIE, Vol. 5273, $35^{\text {th }}$ Annual Boulder Damage Symposium, Boulder CO, 22-24 Sept. 2003, pp. 296-302 (2004).

2. L. M. Kegelmeyer, personal communication (2004).

This work was performed under the auspices of the U.S. Department of Energy by the University of California, Lawrence Livermore National Laboratory under Contract W-7405-Eng-48. 